\title{
Reis, V. \& Tavares, E. (coord.) (2017). Imagem Paradoxal - Francisco Afonso Chaves (1857-1926). Lisboa: Museu Nacional de Arte Contemporânea Museu do Chiado
}

\section{Margarida Medeiros}

Naquele Império, a Arte da Cartografia chegou a tal perfeição que o mapa de uma só Província ocupava toda uma Cidade, e o mapa do Império, toda uma Província. Com o tempo, estes Mapas Desmesurados não eram satisfatórios, e os Colégios de Cartógrafos levantaram um Mapa do Império, que tinha o tamanho do Império e coincidia com ele ponto por ponto.

Menos obcecadas com o Estudo da Cartografia, as Gerações Seguintes entenderam que esse mapa dilatado era Inútil e não sem Impiedade entregaram-no às Inclemências do Sol e dos Invernos. Nos desertos do Oeste perduram despedaçadas, as Ruínas do Mapa, habitadas por Animais e Mendigos; em todo o País não existe outra relíquia das Disciplinas Geográficas"

Suárez Miranda, Viajes de Varones Prudentes, Libro Cuarto, Cap. XLV, Lérida, 1658. Jorge Luis Borges, "O Rigor da Ciência”. In Historia universal de la infâmia, 1948, posteriormente incluída, em 1961, em "El hacedor"

Hoje em dia tudo existe para acabar numa fotografia

(Susan Sontag)

O catálogo que acompanhou as três exposições sobre a obra fotográfica, essencialmente estereoscópica, do coronel Francisco Afonso Chaves (Lisboa - Museu do Chiado, Lisboa - Museu de História Natural, Ponta Delgada - Museu Carlos Machado) constitui-se como um livro de investigação sobre uma das mais extraordinárias coleções portuguesas de fotografia. 
Este livro vem revelar ao panorama português não apenas mais uma série de imagens por acaso descobertas nas reservas do Museu Carlos Machado, mas uma figura ímpar que alia as duas pulsões descritas pelos autores, Borges e Sontag, nas duas epígrafes aqui citadas. O essencial da afirmação de Sontag é ela apontar para a forma como a fotografia veio a dominar a cultura visual a partir do século XIX, acrescentando-se-lhe, ao longo dos séculos XX e XXI o cinema, o vídeo, a televisão, a imagem digital. A razão de ser da citação de Borges é o nomear a compulsão para o mapeamento visual de forma mecânica e objetiva, que, se tem as suas raízes na cartografia, viu na fotografia, a partir do século XIX, o mais eficaz meio de concretização. A demonstração do que valia a pena ser visto, arquivado, memorizado, está indissociavelmente ligada à vida e interesses (naturalismo, oceanografia, exploração geográfica) do autor que é objeto deste livro. E na história da fotografia que mapeia este impulso teremos, a partir desta investigação, de incluir Francisco Afonso Chaves.

O mapa que cobre o Império no texto de Borges fá-lo em tão pequena escala que acaba por coincidir com o mesmo Império, anulando o intervalo entre modelo que descreve e realidade descrita, revelando a sua, afinal, inutilidade, e tornando-o condenado à ruína. Mas o essencial da história remete-nos para essa pulsão de representação exaustiva e visualmente assertiva, que só encontraria na fotografia, para lá dos modelos abstratos e matemáticos, a sua ferramenta de eleição. Se o mapa realista tinha essa limitação que o revelava inútil, o mesmo não se passou com a fotografia. De alguma forma, com a fotografia as coisas funcionaram inversamente: a objetividade mecânica oferecida por esta, e aumentada em termos de realismo táctil pela estereoscopia (táctil ou paratáctil, como refere Victor dos Reis num dos seus textos publicado neste livro) permite apenas visões parciais, razão pela qual o impulso para a exaustividade imagética se tornou inelutável entre muitos viajantes, exploradores, cientistas. Não há conjunto de partes que nos possa dar o todo (mesmo com as panorâmicas há sempre uma redução), mas apenas uma aproximação.

É assim nesta união febril, entre a representação visual do mundo (da paisagem, do clima, das espécies, das pessoas, dos acontecimentos notáveis) e investigação do mesmo, que encontramos a singularidade da obra estereoscópica do naturalista e viajante Francisco Afonso Chaves; na confluência entre saber, investigação e inventário visual, não apenas das coisas sólidas e consistentes, como montanhas, baleias, rochas, pessoas, mas também de outras realidades mais etéreas como vapores, neblinas, luzes ténues. Ou mesmo, tratando de tornar etéreo aquilo que parece substancial.

"A imagem Paradoxal - Francisco Afonso Chaves (1857-1926)" é o resultado de uma investigação em diferentes direções: a pessoa de Afonso Chaves, os amigos, as diferentes vocações (naturalista, meterologista, viajante), as coincidências no tempo e 
no espaço com outras figuras, a sua vocação de incansável explorador e curioso, sempre pronta a extasiar-se perante o que nunca vira. Mas também: as correspondências, os acasos, as insignificâncias que afinal constroem uma vida e lhe dão significado. As múltiplas histórias da vida estereoscópica de Afonso Chaves obrigaram os investigadores a esse trabalho de detetive, lendo cartas, procurando pistas, observando relações.

O livro reúne um conjunto de ensaios, de autores oriundos de diferentes especialidades -fotografia e estereoscopia, naturalismo científico e oceanografia, história da fotografia, história da ciência, curadoria de arte, óptica e estereoscopia. São textos densos, diversos, fascinantes, instrutivos, com os quais aprendemos a ver imagens e a ver a pessoa, com os quais caminhamos numa "história escovada a contrapelo" (expressão de Walter Benjamin), fora das linearidades narrativas, dos personagens óbvios, uma história que se faz de evidências que têm por base uma visão do encontro com a história que não pretende ser mais do que uma forma, subjetiva, de iluminação do passado para que este se possa projetar no presente.

Antes de nos debruçarmos sobre os ensaios, é importante sublinhar a forma como é apresentada a obra fotográfica de Afonso Chaves. Fruto de uma laboriosa colaboração com os designers gráficos, e pelo facto de o efeito estereoscópico não ser passível de ser observado sem o aparelho adequado, cada exemplar traz consigo uma versão simplificada desse mesmo aparelho que, aplicada sobre uma mira inscrita em cada reprodução, nos permite contemplar eficazmente as imagens do livro sem ficarmos reduzidos apenas à informação, ou a uma ideia, abstrata, do que seria a experiência proposta pelo seu autor, e de que ele necessitou; a mera impressão das estereoscopias permitiria apenas ter uma noção extensiva da coleção, mas deixaria de lado a experiência imersiva por ela proposta.

O conjunto dos ensaios procura abordar este espólio a partir de diferentes perspetivas, procurando corresponder à variedade intrínseca desse mesmo espólio, bem como à actividade multidisciplinar do seu autor. Dois dos textos são assinados por um dos curadores da exposição, Victor dos Reis, que tem tido a seu cargo a investigação do espólio desde o seu início. No primeiro, onde reflete sobre a ausência da referência a este espólio nas poucas histórias da fotografia portuguesa, traça o percurso de Afonso Chaves e desta coleção, bem como do seu encontro, acidental, com a mesma. Num segundo texto, "Phosgraphien: o rasto luminoso de certos fenómenos", o mesmo autor desenvolve a análise de algumas séries de fotografias de Afonso Chaves, relacionandoas, quer com a trajetória errante deste (as suas viagens exploratórias pela Europa e África, pelos Oceanos Atlântico e Índico), quer com aspetos particulares da meteorologia, nomeadamente a luminosidade e a trajetória desta na chapa fotográfica, 
onde ao visto se associa o não-visto, o imaginado ou pressentido na experiência da contemplação. E é neste sentido que Reis pode concluir: "Este sujeito vidente não é apenas aquele que é dotado da capacidade de ver, mas aquele que de dotado da capacidade de ver mais (mesmo que para isso seja necessário encontrar numa máquina a necessária extensão das faculdades visuais do seu corpo)" (Reis \& Tavares, 2017: 136).

Outras análises, de entre as inúmeras hipóteses oferecidas por este espólio, nos convidam ao aprofundamento desta vasta coleção. Emília Tavares, co-autora do livro, explora, de forma assertiva, a inserção da obra de Francisco Chaves no contexto, quer da "arte da paisagem", quer das tendências da ciência romântica, espaço teórico no qual a influência de Anthero de Quental e da sua Filosofia da Natureza se faz sentir, "tanto na sua cultura como na sua posição científica" (Reis \& Tavares, 2017: 146). Tanto Reis como Tavares articulam as suas abordagens com a leitura dos diários e correspondência de Afonso Chaves, um ponto fundamental para a fundamentação das suas análises. Conceição Tavares, especialista em História da Ciência, fazendo a sua 'biografia científica', analisa as relações de Chaves com missões oceanográficas como a expedição britânica Challenger, que originou a exploração das profundidades oceânicas e que teria feito escala em São Miguel. A amizade com o Príncipe do Mónaco, cuja dinâmica de campanhas oceanográficas o levaram aos Açores, foi determinante para a extensão dos seus iniciais interesses, da meteorologia e geofísica, para a História Natural (Afonso Chaves far-se-ia fotografar de escafandro). Nicholas Wade, especialista escocês em História da Óptica e da estereoscopia traz um importante contributo para situar Afonso Chaves na História da Estereoscopia, analisando os seus antecedentes e revelando o caráter experimental que a estereoscopia representou para aquele explorador e cientista, nomeadamente o interesse revelado, na coleção, pela fotografia de movimento e pela criação de imagens de aparência 'fantasmagórica'. Finalmente, Victor Flores, especialista em estereoscopia e nas coleções portuguesas de estereoscopia, analisa a relação entre o nascimento dos estudos geodésicos e a utilização da fotografia. Realçando a relação existente entre o uso do teodolito e a fotografia desde o século XIX, nota como, apesar de Afonso Chaves não ter realizado propriamente fototeodolitos, as suas imagens servem para o mesmo propósito: "são imagens que não só localizam a origem das medidas como dão informações sobre as formas do que foi medido, garantindo uma posterior interpretação com acesso ao relevo e distâncias orográficas. Ou seja, estas imagens propiciam que o trabalho de campo se prolongue no laboratório" (Reis \& Tavares, 2017: 77).

Para concluir, e como apreciação global, trata-se de um volume que alarga a história da fotografia portuguesa de forma substancial, decisiva e significativa. Apesar de se tratar 
de um único nome, de um único arquivo (que compreende vários locais, sendo que a maioria das imagens pertence ao Museu Carlos Machado de Ponta Delgada), de uma única obra, o conjunto de artigos proporciona uma análise multidisciplinar e multireferencial que tornam este livro um marco e um exemplo no estudo de coleções fotográficas.

Margarida Medeiros é professora na Faculdade de Ciências Sociais e Humanas da Universidade Nova de Lisboa onde leciona na área da História da Imagem, Fotografia e Cultura Visual. Publicou, entre outros livros e capítulos de livros: Fotografia e Narcisismo - o auto-retrato contemporâneo (Lisboa, Assírio \& Alvim, 2000); Fotografia e Verdade Uma História de Fantasmas (Assírio \& Alvim, 2010); A Última Imagem - fotografia de uma ficção (Documenta, 2012). Recentemente organizou Fotogramas - ensaios sobre a fotografia (Documenta, 2016), reunindo ensaios de diversos autores portugueses.

Em 2014 comissariou a exposição Augusto Bobone, Fotoradiografias, 1896, na Fundação Edp e em 2015, com Emília Tavares, a exposição e catálogo, no Museu Nacional de Arte Contemporânea/ Museu do Chiado e na Galeria Municipal Almeida Garrett do Porto, Tesouros da Fotografia Portuguesa do Século XIX. Foi colaboradora do jornal Público desde o seu início, como crítica de Fotografia, entre 1990 e 2012.

凶margarida.medeiros@fcsh.unl.pt 